EDITORIAL

\title{
Innovaciones en la formación inicial y continua del profesorado: oportunidades y desafíos en el contexto chileno
}

\author{
Innovations in teachers' initial and continuous formation: \\ opportunities and defies in the Chilean context
}

\section{Claudia Contreras Contreras ${ }^{a}$, Carles Monereo Font ${ }^{b}$ COORDINADORES}

\author{
${ }^{a}$ Universidad Austral de Chile, Valdivia. Correo electrónico: claudia.contreras@uach.cl \\ b Universidad Autónoma de Barcelona, Barcelona. Correo electrónico: carles.monereo@uab.cat
}

Los cambios políticos, económicos, demográficos y todos aquellos que afectan a nuestra sociedad, han generado múltiples demandas al sistema educativo, repercutiendo en las necesidades y funciones de los programas de formación del profesorado. Para enfrentar estas nuevas demandas, es necesario que las instituciones que forman al profesorado desarrollen distintos procesos formativos y estrategias que permitan recoger y analizar de manera confiable información acerca del curriculum que ofrecen. Así, también desde el ámbito público, se requiere reunir información acerca de la formación continua diseñada e implementada a lo largo del país, y revisar si las acciones se encaminan efectivamente hacia el logro de las competencias necesarias, para que los profesores y profesoras logren aprendizajes de calidad con sus estudiantes (Fullan y Hargreaves, 2014; Sotomayor y Walker, 2009).

En los últimos años, el tema de la formación docente inicial y continua ha alcanzado una alta notoriedad, particularmente en la discusión política, académica y en los medios de comunicación, debido al trabajo parlamentario y los conflictos, tanto gremiales como estudiantiles, levantados en torno a una nueva legislación. Esto, unido a una revisión de los sistemas educativos, los modelos de evaluación y de certificación de docentes, además de las evaluaciones de los programas de formación y de los sistemas de incentivo, han levantado críticas y necesidades como aspectos centrales que permanecen en la discusión, por ejemplo, a partir de las controversias evidenciadas en la tramitación de la ley de desarrollo profesional docente, vigente a partir de este año (Ley 20.903).

De lo anteriormente planteado, se derivan necesidades de una actualización y transformación constante, que lleva a establecer continuamente nuevos desafíos a los profesionales de la educación y los programas formativos, en particular a quienes trabajan en la formación de profesores, los profesores en formación, los profesores en ejercicio y los directivos, así como también la obligación por parte de la política pública e instituciones universitarias de orientar mayores esfuerzos y recursos en el diseño e implementación de estrategias para el mejoramiento de la formación docente (Hirmas y Cortés, 2013).

Muchas veces se asume que un sistema educativo de calidad depende básicamente de la formación inicial y continua de los docentes que se desempeñan dentro de las aulas. Son 
estos los profesionales llamados a responsabilizarse por el mejoramiento de la enseñanza y alcanzar los aprendizajes con los estudiantes (Cox, Meckes y Bascopé, 2010). Es por esto que hacer un aporte en torno a estos temas resulta relevante, pensando sobre todo en que el foco de la discusión debe centrarse en cómo facilitar procesos que permitan al profesorado desplegar competencias profesionales.

Una de las formas de abordar dichos retos puede llevarse a cabo desde la difusión de investigación y revisiones que aborden en conjunto los aspectos críticos, desafíos y oportunidades encontrados en la formación inicial y el desarrollo profesional de los docentes en el contexto nacional, aportando con ello a la actualización y discusión de estos temas.

En relación con lo anterior, y a partir de algunas interrogantes como, ¿Cuáles son los retos y coyunturas que se encuentran hoy en la formación del profesorado?, ¿Qué desafíos permanecen y se vuelven temas pendientes en Chile?, o, ¿Cómo se asumen temas como la interculturalidad o la articulación teórico-práctica en la formación inicial y continua?, este número temático se propone como una panorámica en torno a las oportunidades y desafíos presentes en la formación docente en Chile.

Cabe considerar que, al abordar la formación docente, se deben visualizar una serie de factores y relaciones que intervienen en sus procesos y resultados. Particularmente en Chile, la precarización de la educación pública y la desregulación de la formación de profesores han sido factores de alto impacto en la formación inicial y continua del profesorado, influyendo en la elección de la carrera, el desarrollo de los programas de formación y los resultados educativos de los futuros profesionales, entre otros asuntos; cuestiones que los autores del presente número han incorporado en sus reflexiones y revisiones, partiendo de la base de que diagnósticos e intervenciones en contexto contribuirán a la asunción adecuada y en perspectiva de estos desafíos.

Bajo una discusión amplia, el título del número actual, aborda "Innovaciones en la formación inicial y permanente del profesorado: oportunidades y desafíos en el contexto chileno". En tal sentido, desde distintos enfoques, los equipos de investigadores y autores individuales abordan la formación inicial y continua del profesorado específicamente con el propósito de divulgar conocimiento en relación a innovaciones y problemáticas emergentes en estos ámbitos, en el contexto nacional.

En este número regular temático, por medio de 15 artículos, once investigaciones y cuatro revisiones, se profundiza en las oportunidades y desafíos que ofrece la formación docente en el contexto del Chile actual.

Desde la visión de los coordinadores de este número temático, resulta relevante hacer un aporte en torno a estos temas, pensando sobre todo en que el foco de la discusión debe centrarse en cómo desarrollar las competencias profesionales de los profesores, potenciando y reuniendo estudios que aborden y problematicen, en este ámbito, tanto la complejidad del fenómeno educativo como los aspectos críticos que influyen en la formación inicial y el desarrollo profesional del profesorado, sopesando las particularidades históricas y contingentes de nuestro país.

Agradecemos a los investigadores e investigadoras, y a los académicos evaluadores, quienes con su trabajo han hecho posible el presente número temático. De la misma manera, agradecemos a la Dirección de Investigación y Desarrollo de la Universidad Austral de Chile, y a la Facultad de Educación de la Universidad de Concepción, por su apoyo para el logro de esta publicación. 


\section{REFERENCIAS BIBLIOGRÁFICAS}

Cox, C., Meckes, L. y Bascopé, M. (2010). La institucionalidad formadora de profesores en Chile en la década del 2000: Velocidad del mercado y parsimonia de las políticas. Pensamiento Educativo, Vols. 46-47, 205-245

Fullan, M. y Hargreaves, A. (2014). Capital Profesional. Madrid: Morata.

Hirmas, C. y Cortés, I. (2015). Investigaciones sobre la formación práctica en Chile: Tensiones y desafios. Santiago de Chile: Organización de Estados Iberoamericanos para la Educación, la Ciencia y la Cultura.

Sotomayor, C. y Walker, H. (2009). Formación continua de profesores. ¿Cómo desarrollar competencias para el trabajo escolar? Santiago de Chile: Editorial Universitaria. 
